\title{
Review
}

\section{Evolution of colour vision in mammals}

\author{
Gerald H. Jacobs* \\ Neuroscience Research Institute and Department of Psychology, University of California, \\ Santa Barbara, CA 93106, USA
}

Colour vision allows animals to reliably distinguish differences in the distributions of spectral energies reaching the eye. Although not universal, a capacity for colour vision is sufficiently widespread across the animal kingdom to provide prima facie evidence of its importance as a tool for analysing and interpreting the visual environment. The basic biological mechanisms on which vertebrate colour vision ultimately rests, the cone opsin genes and the photopigments they specify, are highly conserved. Within that constraint, however, the utilization of these basic elements varies in striking ways in that they appear, disappear and emerge in altered form during the course of evolution. These changes, along with other alterations in the visual system, have led to profound variations in the nature and salience of colour vision among the vertebrates. This article concerns the evolution of colour vision among the mammals, viewing that process in the context of relevant biological mechanisms, of variations in mammalian colour vision, and of the utility of colour vision.

Keywords: colour vision; opsin genes; photopigments; dichromacy; trichromacy; mammals

\section{THE BEGINNINGS}

The earliest true mammals evolved from therapsid ancestors during the Early Jurassic, somewhere around $200 \mathrm{Ma}$. From the analysis of fossils it is usually inferred that these were small animals that were almost certainly nocturnal (Kemp 2005). A capacity for colour vision requires, at minimum, multiple sensors having differing spectral absorption properties that need to be mated to a nervous system capable of contrasting signals that reflect photon absorption rates in the different classes of sensors. Nothing in the fossil record speaks directly to these traits, but some hints can be gleaned from the expanding understanding of the sensors underlying vertebrate colour vision, the cone photopigments, and the opsin genes that specify photopigment proteins.

Some two decades ago, the genes for human cone opsins were isolated and sequenced (Nathans et al. 1986). Subsequent analysis of cone opsin genes from a large number of contemporary animals fostered the development of opsin gene phylogenies. The consensus is that all vertebrate visual photopigments are specified by opsin genes belonging to five gene families, one linked to rod photopigments while the other four underlie cone pigments (Yokoyama 2000; Hisatomi \& Tokunaga 2002). All four of the cone opsin gene families emerged at a point early in vertebrate evolution, perhaps as long as $540 \mathrm{Ma}$ (Collin \& Trezise 2004). Gene-sequence variation within each of these families yields photopigments that can be tuned to absorb preferentially across restricted ranges of peak sensitivities (figure 1, top).

*jacobs@psych.ucsb.edu

One contribution of 13 to a Theme Issue 'The evolution of phototransduction and eyes'.
Of the major contemporary vertebrate groups, representatives of all four cone opsin gene families have been found in various birds, fishes and reptiles, while only three of these have so far been detected in contemporary amphibians (Bowmaker 2008). Mammals depart from these standards.

\section{(a) Monotremes and marsupials}

The lineages leading to present day monotremes, marsupials and eutherians diverged early in mammalian evolution. Although estimates of the timing of these events vary, accounts of mammalian history typically (figure 2) show monotremes diverging from other mammals approximately $166 \mathrm{Ma}$, while marsupial and eutherians subsequently diverged approximately $148 \mathrm{Ma}$.

Recent investigations of cone pigments and opsin genes in monotremes and marsupials shed some light on the early evolution of mammalian colour vision. Examination of cone opsin genes in the monotremes Ornithorhynchus (platypus) and Tachyglossus (echidna) reveal the presence of functional LWS and SWS2 genes (Davies et al. 2007; Wakefield et al. 2008) with in vitro expression of these two genes yielding pigments having absorption peaks $\left(\lambda_{\max }\right)$ at 550 and $451 \mathrm{~nm}$, respectively (Davies et al. 2007). In addition, nonfunctional remnants of an SWS1 gene can be detected. The implication, then, is that at least three cone pigments were likely present in the earliest mammals (drawn from the $S W S 1, S W S 2, L W S$ gene families). During subsequent monotreme evolution, the SWS1 gene degenerated, rendering it non-functional in modern representatives of this lineage.

Examinations of contemporary marsupials expand on this view. Behavioural and electrophysiological studies of the Tammar wallaby (Macropus) isolated 


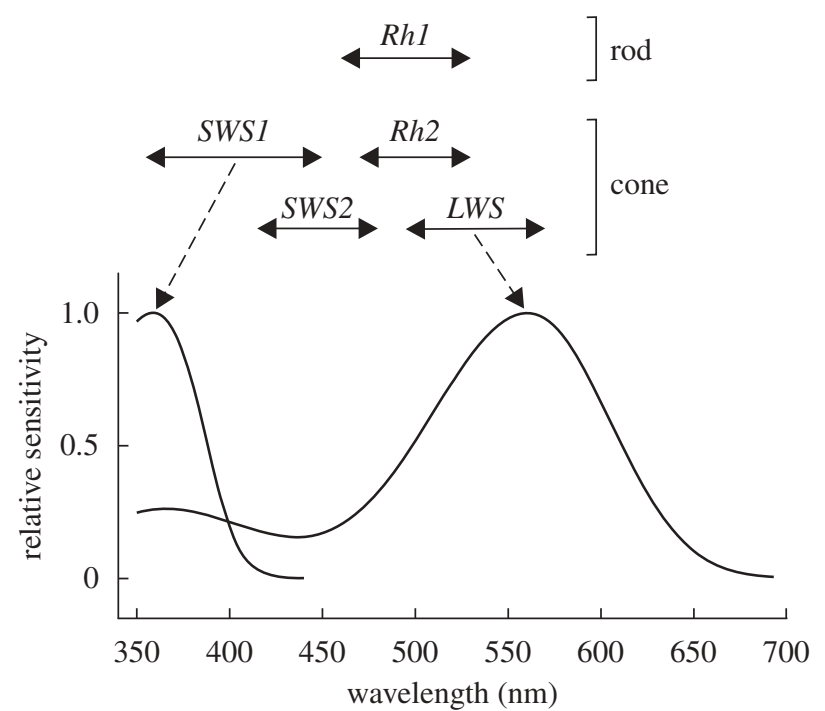

Figure 1. Vertebrate photopigment opsins are products of five opsin gene families (top). In each of these families, gene sequence variations yield photopigments whose $\lambda_{\max }$ values are drawn from the spectral ranges indicated by the extent of the horizontal lines. The ranges shown are those appropriate for pigments constructed using an 11-cis-retinal chromophore. All of the cone photopigments of eutherian mammals come from two of these gene families, SWS1 and $L W S$. It can be inferred from gene sequence comparisons that the two types of cone photopigments found in ancestral members of this group had spectral sensitivities given by the curves at the bottom.

two classes of cones with $\lambda_{\max }$ of 420 and $539 \mathrm{~nm}$, an arrangement shown capable of supporting dichromatic colour vision (Hemmi 1999; Hemmi et al. 2002). Microspectrophotometric (MSP) studies of the photoreceptors of four other Australian marsupials detected three cone types; in each case the retinas contained short- and long-wavelength sensitive pigments and an intermediate third pigment with a peak close to $500 \mathrm{~nm}$ (Arrese et al. 2002, 2005). Based on its spectral positioning, this latter pigment was believed to derive from an opsin gene of the $R h 2$ family (figure 1). Behavioural experiments conducted on one of these species, the fat-tailed dunnart (Sminthopsis crassicaudata), showed that the three cone pigments supported a trichromatic colour vision capacity (Arrese et al. 2006). However, a subsequent examination of cone opsin genes in this same species detected two cone opsin genes, an SWS1 gene and an LWS gene, but found no evidence for the presence of an $R h 2$ gene (Strachan et al. 2004). Recently, Cowing et al. (2008) have extended these results by showing, through in vitro expression, that these two genes code, respectively, for a UV pigment $\left(\lambda_{\max }=363 \mathrm{~nm}\right)$ and an LWS pigment with an absorption peak of $533 \mathrm{~nm}$. The pigment gene/cone photopigment picture for the marsupials thus remains somewhat clouded. It appears that at least some marsupials feature three different types of cone pigment, but confirmation that the third of these is a product of the $R h 2$ gene family is lacking. If the third cone pigment is not from the $R h 2$ gene family, it may instead be that this pigment ( $\lambda_{\max }$ at 505$510 \mathrm{~nm}$ ) is (i) the product of a second $L W S$ gene, so far undetected, or (ii) an $R h 1$ rod pigment expressed in a class of cone. The latter possibility gains support from the observation that the fat-tailed dunnart has two copies of the Rh1 opsin gene (Cowing et al. 2008).

In sum, there is evidence that at least three of the four cone opsin gene families characteristic of the vertebrates were represented in early mammals. Of these, an $S W S 2$ gene persists in the monotremes, but this gene family was subsequently lost at some point prior to the divergence of marsupials and eutherians. Whether the pigment products of Rh2 genes, common in many other vertebrates, were present in early mammals remains uncertain.

\section{(b) Eutherians}

Representatives from two cone opsin gene families appear in contemporary eutherian mammals and, with the exception of some primates, none of these animals derive more than a single photopigment type from each of their two gene families ( $S W S 1$ and $L W S$; figure 1). Given that commonality, what cone pigments may have been present in the retinas of the early eutherians? Sequence comparisons of cone opsin genes have suggested that the ancestral mammalian pigments drawn from these two gene families peaked in the UV, at about $360 \mathrm{~nm}$ (Hunt et al. 2001), and in the long wavelengths at $560 \mathrm{~nm}$ (Yokoyama et al. 2008). Assuming the visual pigment chromophore of early mammals was 11-cis-retinal, the same as that of contemporary mammals, the cone pigments of early eutherian mammals would have had absorption properties similar to those sketched at the bottom of figure 1 .

If these deductions are correct, the retinas of the early eutherians were similar to those of the majority of contemporary mammals in containing two types of cone pigment. Such an arrangement could support dichromatic colour vision. Whether it did would additionally depend on there having been at least some degree of selective expression of the two pigment types in separate receptor classes, on these early mammals having a nervous system organized to allow a contrast of signals from the two types of cone, and on them at least occasionally encountering photic environments sufficiently intense to activate neural comparison circuits. The fact that this basic two cone pigment arrangement is largely conserved among contemporary mammals strongly attests to its adaptive utility in our eutherian ancestors and to its probable role in supporting dichromatic colour vision in these early mammals.

\section{CONE PIGMENTS AND COLOUR VISION IN CONTEMPORARY MAMMALS}

Contemporary mammals successfully colonize an impressive range of natural habitats. For the vast majority of the approximately 5000 species, the visual system provides access to an important source of environmental information. The concern here is with the nature of cone pigment complements of these animals - how these arrangements vary among mammals and what these variations may imply as to the adaptive utility of colour vision. Having summarized above most of what is known about cone pigments 


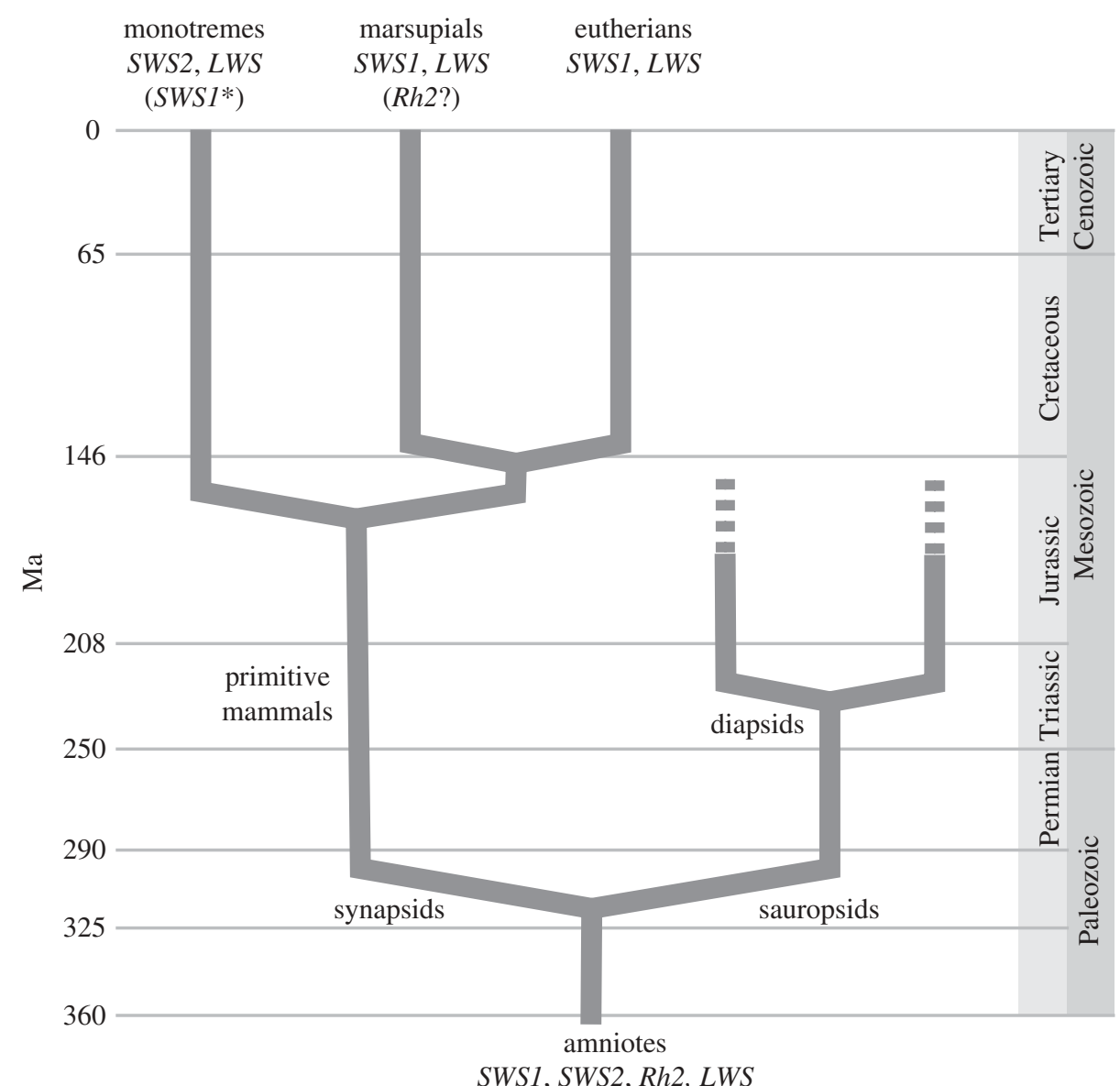

Figure 2. A vertebrate phylogeny illustrating the distribution of the four cone opsin gene families. All four families ( $S W S 1$, $S W S 2, R h 2, L W S$ ) originated early in vertebrate evolution. Of contemporary mammals, monotremes have opsins drawn from the $S W S 2$ and LWS families; these animals also have a non-functional $S W S 1$ opsin gene (asterisk). All eutherian cone pigments are drawn from two families-SWS1 and LWS. Contemporary marsupials have gene representatives from the $S W S 1$ and $L W S$ families and, possibly, from the $R h 2$ gene family. See the text for further discussion.

and colour vision in contemporary monotremes and marsupials, the further focus is on eutherian mammals.

\section{(a) Cone pigment complements in eutherian mammals}

A variety of techniques have been used to measure or infer photopigment complements for a number of mammalian species. The results from many such studies were summarized in earlier reviews (Jacobs 1993; Ahnelt \& Kolb 2000; Kelber et al. 2003). In recent years new insights have often been derived from the developing understanding of the pathways between opsin gene structure and photopigment spectral sensitivity, an approach that has proven to be particularly useful in characterizing species that, because of their rarity or size, would have been difficult to study with traditional methods.

The cone pigment complements of a variety of contemporary mammals are given in table 1 . The list is not comprehensive, but does include at least one species from each of 14 eutherian orders. All of these pigments are linked to two families of cone opsin genes, SWS1 and LWS. Each pigment has in turn been placed into one of four groups according to the inferred or measured spectral location of peak sensitivity: ultraviolet (UV), short wavelength (S), middle wavelength (M), long wavelength (L). Some primates are polymorphic for the $\mathrm{M}$ and $\mathrm{L}$ pigments, or they have both types; primates are considered separately below. Some species also feature non-functional $S W S 1$ cone opsin genes ('absent' in SWS1 pigment in table 1). That issue is considered next.

\section{(b) Loss of function in SWS1 genes}

The mammalian SWS1 opsin genes map to chromosome 7 and specify pigments with $\lambda_{\max }$ ranging from $360 \mathrm{~nm}$ to approximately $445 \mathrm{~nm}$ (figure 1). The retinas of scattered species from at least four mammalian orders (table 1) lack viable cones containing pigments normally linked to these genes. It has long been known that humans diagnosed as having tritanopia, one of the congenital colour vision defects, similarly lack a population of functional $\mathrm{S}$ cones. With the advent of molecular genetic techniques it was learnt that many tritanopes have mutational changes in their S-cone opsin genes that render them non-functional (Weitz et al. 1992), and a similar explanation was shortly thereafter found to account for the absence of viable $S$ cones in two species of non-human primates, the owl monkey (Aotus) and the bushbaby (Galago) (Jacobs et al. 1996b). In recent years, a number of other mammalian species have been found to be similarly afflicted (for a listing of these animals, see Peichl 2005). 
Table 1. Cone pigment complements in some eutherian mammals.

\begin{tabular}{|c|c|c|c|c|}
\hline order & exemplars & SWS1 pigment ${ }^{\mathrm{a}}$ & LWS pigment ${ }^{\mathrm{a}}$ & reference \\
\hline \multirow[t]{6}{*}{ Rodentia } & Mus (mouse) & UV & $M$ & Jacobs et al. (1991) \\
\hline & Rattus (rat) & UV & $\mathrm{M}$ & Jacobs et al. (1991) \\
\hline & Geomys (gopher) & UV & M & Williams et al. (2005) \\
\hline & Cavia (guinea pig) & S & $M$ & Parry \& Bowmaker (2002) \\
\hline & Spermophilus (squirrel) & S & M & Jacobs et al. (1985) \\
\hline & Cricetomys (African rat) & absent & $\mathrm{M} / \mathrm{L}^{\mathrm{b}}$ & Peichl \& Moutairou (1998) \\
\hline \multirow{8}{*}{$\begin{array}{l}\text { Lagomorpha } \\
\text { primate }\end{array}$} & Oryctolagus (rabbit) & S & M & Nuboer et al. (1983) \\
\hline & Macaca (macaque monkey) & $S$ & $\mathrm{M}+\mathrm{L}$ & Schnapf et al. (1988) \\
\hline & Saimiri (squirrel monkey) & $S$ & poly (3) & Mollon et al. (1984) \\
\hline & Aotus (owl monkey) & absent & $\mathrm{L}$ & Jacobs et al. $(1993 b)$ \\
\hline & Alouatta (howler monkey) & S & $\bar{M}+\mathrm{L}$ & Jacobs et al. $(1996 a)$ \\
\hline & Galago (bushbaby) & absent & $\mathrm{L}$ & Deegan II \& Jacobs (1996) \\
\hline & Lemur (ring-tailed) & S & $\mathrm{L}$ & Jacobs \& Deegan II (1993) \\
\hline & Propithecus (sifaka) & S & poly (2) & Tan \& Li (1999) \\
\hline Scandentia & Tupaia (tree shrew) & S & $\mathrm{L}$ & Jacobs \& Neitz (1986) \\
\hline \multirow[t]{2}{*}{ Cetacea } & Eschrichtius (whale) & absent & $\mathrm{L}$ & Levenson \& Dizon (2003) \\
\hline & Tursiops (dolphin) & absent & $\mathrm{L}$ & Fasick et al. (1998) \\
\hline \multirow[t]{3}{*}{ Artiodactyla } & Bos (cow) & S & $\mathrm{L}$ & Jacobs et al. (1994) \\
\hline & Odocoileus (deer) & $S$ & $M$ & Jacobs et al. (1994) \\
\hline & Sus (pig) & $\mathrm{S}$ & $\mathrm{L}$ & Neitz \& Jacobs (1989) \\
\hline Perissodactyla & Equus (horse) & $S$ & $\mathrm{~L}$ & Carroll et al. (2001) \\
\hline \multirow[t]{7}{*}{ Carnivora } & Felis (cat) & $\mathrm{S}$ & $\mathrm{L}$ & Loop et al. (1987) \\
\hline & Canis $(\mathrm{dog})$ & S & $\mathrm{L}$ & Jacobs et al. $(1993 a)$ \\
\hline & Mustela (ferret) & $S$ & $\mathrm{~L}$ & Calderone \& Jacobs (2003) \\
\hline & Ursus (bear) & S & $\mathrm{L}$ & Levenson et al. (2006) \\
\hline & Crocuta (hyena) & $\mathrm{UV} / \mathrm{S}$ & $\mathrm{M} / \mathrm{L}$ & Calderone et al. (2003) \\
\hline & Phoca (seal) & absent & $\mathrm{L}$ & Levenson et al. (2006) \\
\hline & Enhydra (otter) & S & $\mathrm{L}$ & Levenson et al. (2006) \\
\hline Chiroptera & Pteropus (flyng fox) & UV & $\mathrm{L}$ & Wang et al. (2004) \\
\hline Sirenia & Trichechus (manatee) & $\mathrm{S}$ & $\mathrm{L}$ & Newman \& Robinson (2006) \\
\hline Hydracoidea & Procavia (hyrax) & $\mathrm{UV} / \mathrm{S}$ & $\mathrm{M} / \mathrm{L}$ & $\begin{array}{l}\text { L. Peichl, personal } \\
\text { communication }\end{array}$ \\
\hline Proboscidea & Loxodonta (elephant) & S & $\mathrm{L}$ & Yokoyama et al. (2005) \\
\hline Afrosoricida & Echinops (tenrec) & $\mathrm{UV} / \mathrm{S}$ & $\mathrm{M} / \mathrm{L}$ & Peichl et al. (2000) \\
\hline Soricomorpha & Sorex (common shrew) & UV/S & $\mathrm{M} / \mathrm{L}$ & Peichl et al. (2000) \\
\hline
\end{tabular}

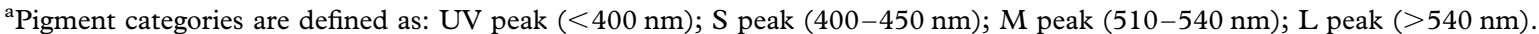

${ }^{b}$ Dual designations are given for pigments detected through the use of opsin immunochemical labelling. At present that technique neither allows a distinction between pigments having UV and S peaks, nor between those that have $M$ and $\mathrm{L}$ peaks.

Unlike tritanopia, a condition impacting only a relative handful of humans (estimated to be no more frequent than 1 in 10000 ), the absences of $S$ cones in these other mammals are very likely species' traits. Explanations for this gene-driven loss of $S$ cones remain, to this point, somewhat elusive. The nonhuman primates in whom this was first discovered are strongly nocturnal suggesting that since contributions to seeing from S-cone signals are principally linked to colour vision, a capacity mostly useful at light levels higher than those characteristic of the visual environments of these animals, their absence might have little impact on visual success. Many of the other species subsequently shown to be without $S$ cones are also nocturnal, thus promoting the same linkage. If, however, that is the explanation, it is curious as to why so many other nocturnal mammals (including some listed in table 1) retain a complement of functional $S$ cones. Further, the fact that these gene mutations have spread throughout the populations allows the possibility that the loss of $S$ cones may in some way enhance visual fitness.

In sum, although it is not the norm, a number of mammalian species have lost their S-cone photopigments as a result of opsin gene mutation. The nature of the inactivating mutation differs across groups of such animals, and the loss has occurred at different stages of lineage evolution, sometimes near the base of the radiation, sometimes in more derived lines (Levenson et al. 2006). This loss of function shows some correlation with the photic activity cycle, being seen mostly in species typically described as nocturnal, but that behaviour is not always linked to such loss. Indeed, if it were, it seems possible that functional SWS1 genes would have been lost to all contemporary mammals given the long nocturnal phase of early mammalian evolution. Because this loss is seen in widely divergent species, animals often sharing little in common with regard to either phylogeny or photic environment, there are probably multiple circumstances that permit, or even support, a gene-driven loss of a complete cone class and along with it the potential for a dimension of colour vision.

\section{(c) Spectral positioning of mammalian cone pigments}

The retinas of most eutherian mammals feature two classes of cones-one containing an SWS1 pigment, 
the other an LWS pigment, a pairing that in all cases so far studied provides the pigment basis for a single dimension of colour vision. The relative spectral positioning of the cone pigments varies widely among mammals and it is natural to ask if there are some particular aspects of their vision that might explain these variations. Proceeding from the idea that pigment positioning is adaptive, some investigators have pursued a modelling approach to this question that starts with spectral measurements of natural objects and illuminants and then, through calculation, asks what pigment combinations should provide the best substrate for colour discrimination (e.g. Lythgoe \& Partridge 1989; Osorio \& Vorobyev 1996; Chiao et al. 2000). Although the assumptions of the models vary, the outcomes of these exercises generally agree that with an SWS pigment having $\lambda_{\max }>400 \mathrm{~nm}$ (denoted as $S$ in table 1), variations in the spectral positioning of the LWS cone from its longest to its shortest position (figure 1) have surprisingly modest effects on predicted colour discrimination capabilities. In addition, for most viewing conditions it appears that (i) it would not prove beneficial to shift the $S$ pigment towards the longer wavelengths and (ii) that for purposes of colour discrimination in these dichromatic systems it is generally advantageous to increase the spectral separation of the two pigments, irrespective of the details of the photic environment.

Assuming that these models reasonably predict colour vision performance under natural conditions and that the LWS pigment in the ancestral eutherian mammal had a $\lambda_{\max }$ at approximately $560 \mathrm{~nm}$ (figure 1), it is not obvious why the position of this pigment has very frequently been shifted towards the shorter wavelengths. Consideration of those aspects of mammalian vision that do not involve colour does not seem to help. In mammals, those features of seeing that are based on utilization of luminance differences are supported by signals from the LWS pigment(s). For daylight illuminant spectra, quantal capture is maximized by having the cone pigment shifted as far as possible towards the longer wavelengths. For other common terrestrial photic environments, for instance, light filtered through a leafy environment, quantal capture is about the same for all LWS pigment positions (Osorio \& Vorobyev 2005). In short, at present there seems to be no general adaptive explanations for the diversity of spectral positions of the LWS cones in dichromatic mammals. Thus far, phylogenetic relationships seem to provide the strongest predictor of the positioning of the LWS pigment in dichromatic mammals and this may suggest that detailed consideration of visual demands and opportunities experienced by specific mammalian lineages might provide some leverage on this issue.

To date these models have not been applied to evaluate those rodents that have UV pigments (table 1). UV signals are known to play important roles in the visual behaviours of some vertebrates, particularly in birds, and that linkage suggests that this may also be the case for these rodents. There has been little investigation on this issue. One suggestion is that under photopic lighting conditions, rodents might use signals from their UV cones to detect the presence of fresh urinary markings which feature heightened UV reflectivity (Chavez et al. 2003). In the only direct examination of possible functional utility of mammalian UV cones, it was found that foraging mice behave with indifference in the presence or absence of food-relevant UV signals (Honkavaara et al. 2008). Whether UV sensitivity may offer some alternative advantages is not known and thus there is currently no explanation for why, alone among eutherian mammals, a number of rodents have retained UV cones.

\section{(d) Roles for rods}

The retinas of all mammals contain both rods and cones, but there are impressive species variations in the relative representation of the two receptor types. It has long been known that these variations generally correlate with the normal photic environment of the animal, and a recent quantitative study of the anatomy of the central and peripheral parts of the visual system in a number of nocturnal and diurnal species establishes that, indeed, there are large niche-specific variations in the receptor complement (Kaskan et al. 2005). The response of the retina to environmental pressures can be dramatic. For instance, even though it has a smaller retina, the nocturnal rat has eight times more rods than does the highly diurnal ground squirrel-in rat about 1 per cent of all receptors are cones, while the comparable figure for the ground squirrel is approximately 86 per cent. At least two differences seem linked to this disparity. First, there are many more output fibres from the retina carrying colour signals in the ground squirrel than in the rat. Second, since the signal-to-noise ratio should be improved by summing signals across cone populations, increases in local cone density might be expected to enhance the salience of colour signals in the visual system. Both of these features predict variations in robustness of the colour capacity. Formal tests of colour vision seem to support this idea. Both rat and ground squirrel have two types of cone and both can be formally shown to have dichromatic colour vision, but that capacity is much easier to demonstrate in the cone-rich ground squirrel than it is in the conepoor rat (Jacobs \& Yolton 1971; Jacobs et al. 2001). Comparative studies usually focus on the number of cone types and on their spectral sensitivity, but for predictions about the utility of colour vision an understanding of the rod/cone weighting is also apt to be highly relevant.

Rods can also influence mammalian colour vision in more direct ways. In all duplex visual systems, rods and cones operate in common over a considerable range of retinal illuminances: for example, in the case of human vision across some four log units of light intensity. Rod and cone signals have multiple locations of potential interaction in the retina and they course along shared output pathways into the central visual system. In humans, rod signals can be shown to influence colour perception in complex ways (Buck 2004); in fact, under the right conditions of viewing rod and cone signals can be contrasted to yield an additional dimension of colour vision (Smith \& Pokorny 1977). 
Rod influences on colour vision remain virtually unstudied in other mammals, but given that many of these species are normally most active under lighting conditions that should support joint rod and cone function, rod contributions to mammalian colour vision may well turn out to be of great importance.

\section{(e) Primate colour vision is a special case}

Although three (or more) types of cone pigments are common among vertebrates, in eutherian mammals only primates have three cone pigments, and even among them that arrangement is far from universal. Research conducted in recent years has greatly advanced our understanding of the distribution and evolution of primate colour vision. References to the now numerous original articles on these topics can be found in several recent reviews (Regan et al. 2001; Osorio et al. 2004; Jacobs 2007, 2008).

The first primates appeared at $80-90 \mathrm{Ma}$ (Bininda-Emonds et al. 2007; Springer \& Murphy 2007). Although the idea is sometimes disputed (e.g. Tan et al. 2005), these early primates are generally believed to have been nocturnal (Martin \& Ross 2005), and thus, like those of most eutherian mammals, their retinas probably featured single representative pigments from the SWS1 and LWS gene families, supporting dichromatic colour vision. Subsequently, many primate lineages became diurnal, fostering an enhanced dependence on vision and setting the stage for alterations in photopigments and colour vision. LWS opsin genes in mammals are on the X-chromosome. All contemporary catarrhine primates (Old World monkeys, apes, humans) have two LWS genes that are positioned in a head-to-tail tandem array. These genes specify spectrally discrete cone pigments ( $\lambda_{\max }$ values of approx. 530 and $560 \mathrm{~nm}$, usually termed $M$ and L). In conjunction with an $S W S$-derived pigment, this provides three cone pigments that support a capacity for trichromatic colour vision (figure $3 a$ ). The $\mathrm{M}$ and $\mathrm{L}$ photopigments were apparently derived from duplication of the original X-chromosome opsin gene (Nathans et al. 1986). Since this three-pigment arrangement is not generally shared with members of the other major anthropoid group, the New World platyrrhine monkeys, but is common to all catarrhines, the $\mathrm{X}$-chromosome opsin gene duplication is believed to have occurred at the base of the catarrhine radiation, some 30-40 Ma.

In distinction to these Old World primates, platyrrhine monkeys feature more varied opsin gene/colour vision arrangements. Most of the species in this group have X-chromosome opsin-gene polymorphisms, typically featuring three alternative versions of the $L W S$ gene, each of which specifies a cone pigment with a $\lambda_{\max }$ in the range of approximately 530 and $560 \mathrm{~nm}$ (figure $3 b$ ). Such an arrangement yields a total of six discrete photopigment phenotypes. Male monkeys and homozygous females express any one of the three $L W S$ opsin genes and, in conjunction with the $S W S$ gene common to all individuals, then have any of the three combinations of two photopigments. Heterozygous females have different LWS genes

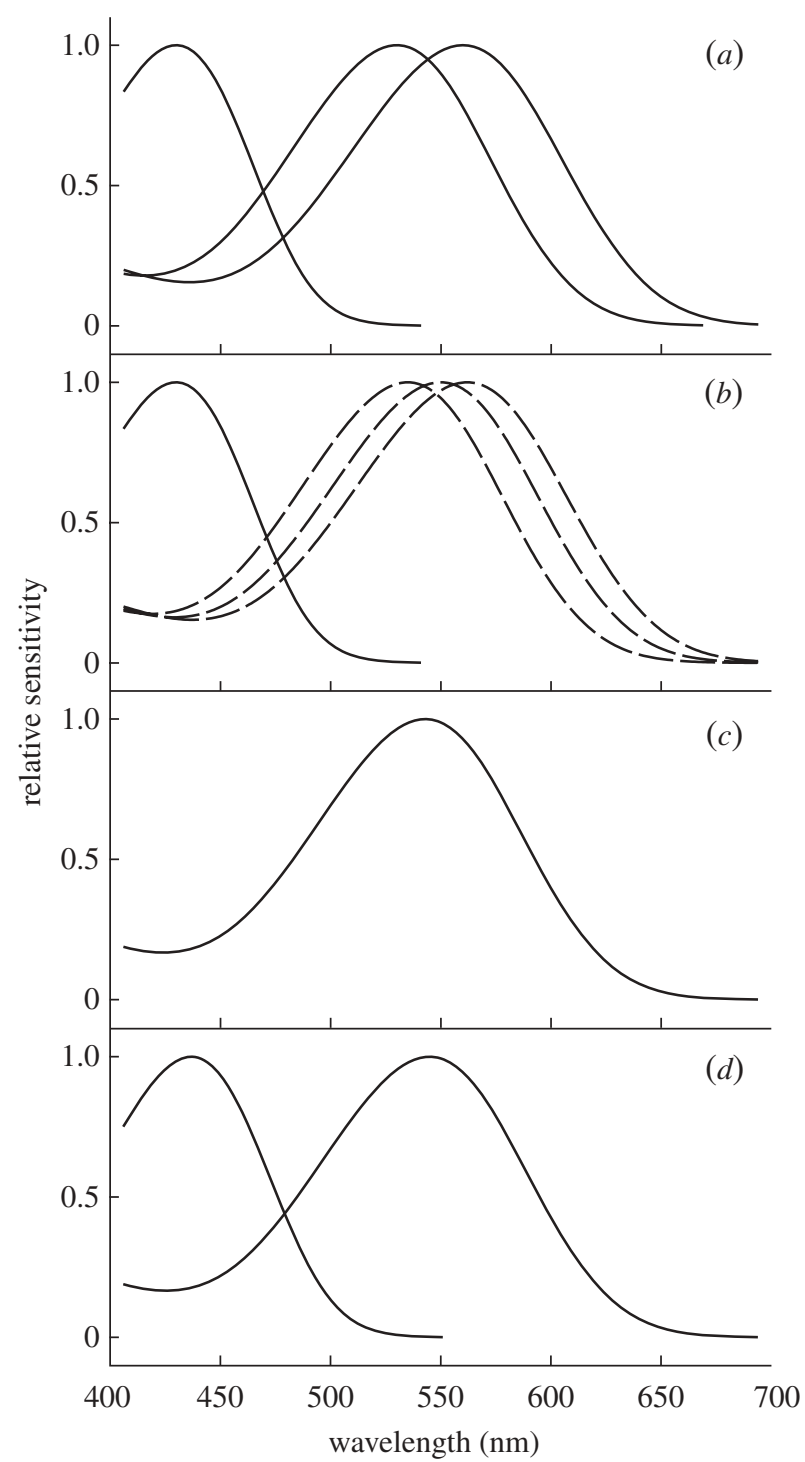

Figure 3. Variations in primate cone photopigment arrangements. (a) All catarrhine primates and the platyrrhine howler monkey have three classes of cone pigments that support trichromatic colour vision. (b) Many platyrrhine monkeys have polymorphic colour vision in which all male monkeys and homozygous females get any of three $\mathrm{M} / \mathrm{L}$-cone pigments (dashed lines) which in conjunction with the $\mathrm{S}$ pigment supports dichromatic colour vision. Female platyrrhine monkeys that are heterozygous have any pair of the $\mathrm{M} / \mathrm{L}$ pigments and they are trichromatic. (c) The platyrrhine Aotus monkey and a number of strepsirrhine primates have only a single cone photopigment and thus lack a colour vision capacity. (d) Some strepsirrhine monkeys have two types of cone photopigment and dichromatic colour vision.

on their X-chromosomes and, for them, the early developmental process of random X-chromosome inactivation results in a retina that contains three classes of cone pigments. Since there are three possible pairings of the LWS pigments, there are also three types of heterozygous females. When they are tested behaviourally, animals having each of these types of pigment arrays are found to have colour vision that is predictable from the pigment complement, i.e. animals with two pigments are dichromatic, those with three are trichromatic (Jacobs 2007).

Two genera of platyrrhine monkeys depart from this general polymorphic pattern. As already noted, the 
nocturnal owl monkey (Aotus) has a non-functional Sopsin gene so this primate has only a single type of cone pigment (figure $3 c$ ) and thus lacks the capacity for conventional colour vision (Jacobs et al. 1993b). The howler monkey (Alouatta), on the other hand, is similar to the catarrhines in having two different $\mathrm{X}$-chromosome opsin genes and separate populations of cones containing S, M and L pigments (figure $3 a$ ), allowing for trichromatic colour vision (Araujo Jr. et al. 2008). Howler monkeys are the only platyrrhine monkeys to have achieved species-wide trichromacy.

The third large group of primates, the more primitive strepsirrhines, presents an even more varied picture of opsin genes and cone photopigments. Examples of three different arrangements are listed in table 1. Some, such as the bushbaby Galago are similar to the owl monkey in having a non-functional S-opsin gene and a single $\mathrm{L}$ pigment (figure $3 c$ ). Such animals presumably lack colour vision. Another is exemplified by the ring-tailed lemur (Lemur catta) which has a functional S-cone pigment and a single $\mathrm{L}$ pigment, an arrangement predicting dichromatic colour vision (figure $3 d$ ). A third variant has been detected in strepsirrhines such as the Sifakas (Propithecus). In addition to an S-cone pigment, these animals feature two polymorphic LWS pigments. Although not yet evaluated behaviourally, it seems likely that heterozygous females from this group will have two different forms of trichromatic colour vision while, similar to the polymorphic platyrrhines, males and homozygous females will be obligate dichromats.

This brief account illustrates that some primate lineages have been able to expand their colour capacities beyond those characteristics of other mammals by adding a third class of cone pigment, thus allowing them to achieve an additional dimension of colour vision. What factors might have supported this change?

Alterations in opsin genes can change the spectral absorption properties of photopigments. At minimum, a mutation that results in the substitution of a single nucleotide can be sufficient to produce a spectral shift in the photopigment encoded by that gene (Merbs \& Nathans 1993; Asenjo et al. 1994). If this mutated gene then comes under positive selection, a polymorphic version of the pigment will emerge in the population. Just such a scenario probably underlies the high-frequency polymorphism of the LWS genes seen in some platyrrhine and strepsirrhine primates. A potential limitation in cases like this is that any visual advantages linked to the presence of a new allele cannot be equally shared by all members of the population. Full species representation of the new pigment can be achieved through opsin gene duplication, as apparently happened early in catarrhine evolution. It remains unclear whether photopigment polymorphisms, which support a mixture of colour vision phenotypes in the population, stand as a typical intermediate stage on the way to routine trichromacy or whether the two arrangements represent independent evolutionary trajectories. Details of the arrangement of the X-chromosome opsin gene array in the howler monkey, the only platyrrhine to achieve species-wide trichromacy, strongly imply that at least in this one case $\mathrm{M} / \mathrm{L}$ pigment polymorphism was preliminary to routine trichromacy (Dulai et al. 1999).

There is no evidence for evolution of a third cone pigment in any non-primate eutherian mammal. One possible reason for this is that survival of a new pigment may depend on the prior presence of an appropriate population of cones and on a nervous system that is organized so as to be able to take advantage of any information the added pigment may provide. The retinas of many mammals contain only small cone populations. In such cases, signals emerging from only a relative handful of receptors containing a new pigment might prove ineffective in reliably supporting any new discriminatory capacity and thus may fail to evolve. And even if there is a sufficient population of cones, acquisition of a new colour vision capacity also requires that signals from the new cone type be neurally compared with those from another cone class. There are two circuits in mammalian retinas known to support such comparisons (Martin 1998; Lee 2004). One involves a class of ganglion cell that receives antagonistic inputs from S/UV cones and $\mathrm{M}$ / $\mathrm{L}$ cones resulting in a spectrally opponent signal being fed forward into the visual system. Opponent signals of this type are capable of supporting a capacity for colour vision (Solomon \& Lennie 2007). The other circuit originates from the antagonistic combination of signals from $\mathrm{M}$ and $\mathrm{L}$ cones in the so-called midget cell system. Although the evidence is limited, the first of these circuits is believed to be common to the retinas of all eutherian mammals, while the second arrangement is unique to primates. Because the midget cell system has been identified in species from all three of the large primate groupings, including those that have only a single type of $\mathrm{M} / \mathrm{L}$ cone, it has been suggested that the midget cell system evolved early in primate history, perhaps to support heightened visual acuity, and that its presence then provided an efficient neural substrate, so that the emergence of a novel $\mathrm{M} / \mathrm{L}$ pigment immediately yielded a new dimension of colour vision (Wässle 2004). In this view, the absence of a midget cell system in the retinas of mammals other than primates is an important factor limiting the expansion of their colour vision. Evidence that such absence may not present an absolute barrier is contained in a recent demonstration that mice whose retinas were engineered to contain a third class of cone pigment did gain some novel colour vision even though this species lacks a retinal midget cell system (Jacobs et al. 2007).

Given these building blocks, what features of primate life supported the evolution of a new dimension of colour vision? It is a long-held idea that since many primates are frugivores, and since ripened fruits can offer distinctive chromatic signals, the evolution of the dimension of primate colour vision supported by $\mathrm{M} / \mathrm{L}$ pigments is causally linked to the harvest of fruits (e.g. Regan et al. 2001). In recent years, a number of computational models of colour vision have been employed to test whether the primate $\mathrm{M} / \mathrm{L}$ pigments are well suited to underlie the discrimination of fruits embedded in foliage. The consistent answer is that they are (Osorio \& Vorobyev 1996; Regan et al. 2001; Parraga et al. 2002). However, 
model computations also show that there are other classes of critical behaviours, for example discrimination of edible foliage or of variations in skin coloration, which would be similarly well served by the $\mathrm{M} / \mathrm{L}$ dimension of primate colour vision (Dominy \& Lucas 2001; Changizi et al. 2006). So far, it appears that model studies alone are incapable of clearly identifying those aspects of primate life that impacted the evolution of their colour vision.

Another approach in trying to understand how primate colour vision evolved is to examine directly how behaving animals exploit colour information. For this purpose, the polymorphic platyrrhines have provided an invaluable resource, since we know that (i) opsin gene polymorphisms responsible for the colour vision variations in platyrrhine monkeys have been maintained by natural selection over long periods of time (Boissinot et al. 1998; Surridge et al. 2003) and (ii) individual monkeys in these species are forced to deploy strikingly different colour vision capacities to achieve common life-supporting goals. Studies of such species can ask, for instance, whether animals with alternative colour vision arrangements are better or worse at particular foraging tasks. In tests run under semi-natural conditions, trichromatic monkeys proved to be more efficient at gathering foods predicated on the use of colour cues than were dichromatic conspecifics (Caine \& Mundy 2000; Smith et al. 2003). Although such outcomes imply that trichromacy could have evolved in the service of efficiency in food harvesting, other research suggests that the story may be more complicated than that. For instance, several sets of observations made on monkeys feeding in natural circumstances found no causal relationships between colour vision status and efficiency in foraging (Dominy et al. 2003; Smith et al. 2003; Vogel et al. 2007). Supporting this conclusion is a recent examination of the efficiency of fruit gathering in polymorphic spider monkeys (Ateles) that also detected no differences between dichromatic and trichromatic animals (Hiramatsu et al. 2008). This experiment focused specifically on foraging that is conducted over very short range (within an arms length) and the physical feature of the target fruits that best predicted foraging efficiency was not colour, but rather luminance contrast, a cue that should be equally available to trichromatic and dichromatic viewers (Hiramatsu et al. 2008). It may be noted that short-range foraging such as this also allows for the exploitation of various non-visual cues (e.g. Dominy et al. 2001).

Researchers have had little difficulty in identifying potential advantages that might explain why colour vision evolved in the way that it has among the primates, but so far have had less success in demonstrating which among these may hold greater importance or, indeed, whether any single set of circumstances may provide a general explanation. Future studies on this topic will no doubt continue to exploit the exceptional opportunities for study offered by the polymorphic platyrrhine monkeys, while having to pay closer attention to the physical details of the viewing environment operative for a range of natural behaviours.

\section{MAMMALIAN COLOUR VISION: THE COMPARATIVE CONTEXT}

As a result of events that occurred during the early history of mammals, eutherian mammals retain only two of the four cone opsin gene families found in many other vertebrates. Very likely during this same time frame, the elaborate system of coloured oil droplets characteristic of photoreceptors in many vertebrates were also abandoned, as was a portion of the specific retinal circuitry dedicated to processing colour information (Jacobs \& Rowe 2004). These changes left most eutherian mammals with a single dimension of colour vision. Primates subsequently escaped this restriction by evolving a series of visual system alterations that provided opportunities for expanded colour vision. These changes, that are quite variable across different primate lineages, include a greatly enhanced population of cones densely organized around a centralized fovea, the addition of a third type of cone photopigment, and the appearance of retinal circuitry that facilitates the comparison of signals from different cone classes.

Viewed in comparison with other animals, many of which feature much more elaborate peripheral adaptations for extracting colour information, it is perhaps appropriate that mammals are routinely described as having impoverished colour vision (e.g. Goldsmith 2006). Despite its apparent simplicity, however, the maintenance of a colour vision capacity throughout the long history of eutherian mammals argues that it must have played a useful role in supporting mammalian success. Comparative judgements about the relative limitations of mammalian colour vision are sometimes extended to include the primates, but it is a lot less clear that this step is justified. Consider, for example, that under stringent test conditions human trichromats can be shown to make reliable colour discriminations based on wavelength differences of as little as $0.25 \mathrm{~nm}$ (Mollon et al. 1990), and that the total number of surface colours that trichromatic humans can discern may be upwards of approximately 2.3 million (Pointer \& Attridge 1998). So far, it seems not to have been demonstrated that any other species can match these rather impressive performances. In any case, perhaps the major strength of primate colour vision comes not just from the keenness of their discrimination abilities, which are considerable, but rather from the fact that primates have evolved a large, agile and plastic brain that allows them to use colour information in a multitude of ways generally unavailable to those species with more limited central processing capability.

I thank Mickey Rowe and three anonymous referees for helpful comments. Preparation of this review was supported by a grant from the National Eye Institute (EY002052).

\section{REFERENCES}

Ahnelt, P. K. \& Kolb, H. 2000 The mammalian photoreceptor mosaic-adaptive design. Prog. Retinal Eye Res. 19, 711-770. (doi:10.1016/S1350-9462(00)00012-4)

Araujo Jr, A. C., Didonet, J. J., Araujo, C. S., Saletti, P. G., Borges, T. R. J. \& Pessoa, V. F. 2008 Color vision in the 
black howler monkey (Alouatta caraya). Vis. Neurosci. 25, 243-248.

Arrese, C. A., Hart, N. S., Thomas, N., Beazley, L. D. \& Shand, J. 2002 Trichromacy in Australian marsupials. Curr. Biol. 12, 657-660. (doi:10.1016/S0960-9822(02) 00772-8)

Arrese, C. A., Oddy, A. Y., Runham, P. B., Hart, N. S., Shand, J., Hunt, D. M. \& Beazley, L. D. 2005 Cone topography and spectral sensitivity in two potentially trichromatic marsupials, the quokka (Setonix brachyurus) and quenda (Isodon obesulus). Proc. R. Soc. B 272, 791796. (doi:10.1098/rspb.2004.3009)

Arrese, C. A., Beazley, L. D. \& Neumeyer, C. 2006 Behavioural evidence of marsupial trichromacy. Curr. Biol. 16, R193-R194. (doi:10.1016/j.cub.2006.02.036)

Asenjo, A. B., Rim, J. \& Oprian, D. D. 1994 Molecular determinants of human red/green color discrimination. Neuron 12, 1131-1138. (doi:10.1016/0896-6273(94) 90320-4)

Bininda-Emonds, O. R. P. et al. 2007 The delayed rise of present-day mammals. Nature 446, 507-512. (doi:10. 1038/nature05634)

Boissinot, S., Tan, Y., Shyue, S.-K., Schneider, H., Sampaio, I., Neiswanger, K., Hewett-Emmett, D. \& Li, H. 1998 Origins and antiquity of $\mathrm{X}$-linked triallelic color vision systems in New World monkeys. Proc. Natl Acad. Sci. USA 95, 13 749-13 754. (doi:10.1073/pnas.95.23.13749)

Bowmaker, J. K. 2008 Evolution of vertebrate visual pigments. Vision Res. 48, 2022-2041. (doi:10.1016/j.visres. 2008.03.025)

Buck, S. L. 2004 Rod-cone interactions in human vision. The visual neurosciences, vol. 1 (eds L. M. Chalupa \& J. S. Werner), pp. 863-878. Cambridge, UK: MIT Press.

Caine, N. G. \& Mundy, N. I. 2000 Demonstration of a foraging advantage for trichromatic marmosets (Callthrix geoffroyi) dependent on food colour. Proc. R. Soc. B 267, 439-444. (doi:10.1098/rspb.2000.1019)

Calderone, J. B. \& Jacobs, G. H. 2003 Spectral properties and retinal distributions of ferret cones. Vis. Neurosci. 20, $11-17$

Calderone, J. B., Reese, B. E. \& Jacobs, G. H. 2003 Topography of photoreceptors and retinal ganglion cells in the spotted hyena (Crocuta crocuta). Brain Behav. Evol. 62, 182-192. (doi:10.1159/000073270)

Carroll, J., Murphy, C. J., Neitz, M., Ver Hoeve, J. N. \& Neitz, J. 2001 Photopigment basis for dichromatic color vision in the horse. F. Vision 1, 80-87. (doi:10. $1167 / 1.2 .2)$

Changizi, M. A., Zhang, Q. \& Shimojo, S. 2006 Bare skin, blood and the evolution of primate colour vision. Biol. Lett. 2, 217-221. (doi:10.1098/rsbl.2006.0440)

Chavez, A. E., Bozinovic, F., Peichl, L. \& Palacios, A. G. 2003 Spectral sensitivity, fur coloration, and urine reflectance in the genus Octodon (Rodentia): implications for visual ecology. Invest. Ophthalmol. Vis. Sci. 44, 2290-2296. (doi:10.1167/iovs.02-0670)

Chiao, C.-C., Vorobyev, M., Cronin, T. W. \& Osorio, D. 2000 Spectral tuning of dichromats to natural scenes. Vision Res. 40, 3257-3271. (doi:10.1016/S00426989(00)00156-5)

Collin, S. P. \& Trezise, A. E. O. 2004 The origins of colour vision in vertebrates. Clin. Exptl. Optom. 87, 217-233. (doi:10.1111/j.1444-0938.2004.tb05051.x)

Cowing, J. A., Arrese, C. A., Davies, W. L., Beazley, L. D. \& Hunt, D. M. 2008 Cone visual pigments in two marsupial species: The fat-tailed dunnart (Sminthopsis crassicaudata) and the honey possum (Tarsipes rostratus). Proc. R. Soc. B 275, 1491-1499. (doi:10.1098/rspb.2008.0248)

Davies, W. L., Carvalho, L. S., Cowing, J. A., Beazley, L. D., Hunt, D. M. \& Arrese, C. 2007 Visual pigments of the platypus: a novel route to mammalian colour vision. Curr. Biol. 17, R161-R163. (doi:10.1016/j.cub.2007. 01.037)

Deegan II, J. F. \& Jacobs, G. H. 1996 Spectral sensitivity and photopigments of a nocturnal prosimian, the bushbaby (Otolemur crassicaudatus). Am. F. Primatol. 40, 55-66. (doi:10.1002/(SICI) 1098-2345(1996)40:1<55:: AID-AJP4>3.0.CO;2-\#)

Dominy, N. J. \& Lucas, P. W. 2001 Ecological importance of trichromatic colour vision to primates. Nature 410, $363-$ 365. (doi:10.1038/35066567)

Dominy, N. J., Lucas, P. W., Osorio, D. \& Yamashita, N. 2001 The sensory ecology of primate food perception. Evol. Anthopol. 10, 177-188.

Dominy, N. J., Garber, P. A., Bicca-Marques, J. C. \& Azevedo-Lopes, M. A. 2003 Do female tamarins use visual cues to detect fruit rewards more successfully than do males? Anim. Behav. 66, 829-837. (doi:10. 1006/anbe.2003.2288)

Dulai, K. S., von Dornum, M., Mollon, J. D. \& Hunt, D. M. 1999 The evolution of trichromatic color vision by opsin gene duplication in New World and Old World primates. Genome Res. 9, 629-638.

Fasick, J. I., Cronin, T. W., Hunt, D. M. \& Robinson, P. R. 1998 The visual pigments of the bottlenose dolphin (Tursiops truncatus). Vis. Neurosci. 15, 643-651.

Goldsmith, T. H. 2006 What birds see. Sci. Am. 295, 68-75.

Hemmi, J. M. 1999 Dichromatic colour vision in an Australian marsupial, the tammar wallaby. F. Comp. Physiol. A 185, 509-515. (doi:10.1007/s003590050411)

Hemmi, J. M., James, A. \& Taylor, W. R. 2002 Color opponent retinal ganglion cells in the tammar wallaby retina. F. Vision 2, 608-617. (doi:10.1167/2.9.3)

Hiramatsu, C., Melin, A. D., Aureli, F., Schaffner, C. M., Vorobyev, M., Matsumoto, Y. \& Kawamura, S. 2008 Importance of achromatic contrast in short-range fruit foraging of primates. PLOS One 3, e3356. (doi:10.1371/ journal.pone.0003356)

Hisatomi, O. \& Tokunaga, F. 2002 Molecular evolution of proteins involved in vertebrate phototransduction. Comp. Biochem. Physiol. B 133, 509-522. (doi:10.1016/ S1096-4959(02)00127-6)

Honkavaara, J., Aberg, H. \& Viitala, J. 2008 Do house mice use UV cues when foraging? f. Ethol. 26, 339-345. (doi:10.1007/s10164-007-0068-6)

Hunt, D. M., Wilkie, S. E., Bowmaker, J. K. \& Poopalasundaram, S. 2001 Vision in the ultraviolet. Cell. Mol. Life Sci. 58, 1583-1598. (doi:10.1007/PL00000798)

Jacobs, G. H. 1993 The distribution and nature of colour vision among the mammals. Biol. Rev. 68, 413-471. (doi:10.1111/j.1469-185X.1993.tb00738.x)

Jacobs, G. H. 2007 New World monkeys and color. Internal. f. Primatol. 28, 729-759. (doi:10.1007/s10764-0079168-y)

Jacobs, G. H. 2008 Primate color vision: a comparative perspective. Vis. Neurosci. 25, 619-633. (doi:10.1017/ S0952523808080760)

Jacobs, G. H. \& Deegan II, J. F. 1993 Photopigments underlying color vision in ringtail lemurs (Lemur catta) and brown lemurs (Eulemur fulvus). Am. F. Primatol. 30, 243-256. (doi:10.1002/ajp.1350300307)

Jacobs, G. H. \& Neitz, J. 1986 Spectral mechanisms and color vision in the tree shrew (Tupaia belangeri). Vision Res. 26, 291-298. (doi:10.1016/0042-6989(86)90026-X)

Jacobs, G. H. \& Rowe, M. P. 2004 Evolution of vertebrate colour vision. Clin. Exp. Optom. 87, 206-216. (doi:10. 1111/j.1444-0938.2004.tb05050.x)

Jacobs, G. H. \& Yolton, R. L. 1971 Visual sensitivity and color vision in ground squirrels. Vision Res. 11, 511539. (doi:10.1016/0042-6989(71)90074-5) 
Jacobs, G. H., Neitz, J. \& Crognale, M. 1985 Spectral sensitivity of ground squirrel cones measured with ERG flicker photometry. F. Comp. Physiol. A 156, 503-509. (doi:10. 1007/BF00613974)

Jacobs, G. H., Neitz, J. \& Deegan II, J. F. 1991 Retinal receptors in rodents maximally sensitive to ultraviolet light. Nature 353, 655-656. (doi:10.1038/ 353655a0)

Jacobs, G. H., Deegan II, J. F., Crognale, M. A. \& Fenwick, J. A. 1993a Photopigments of dogs and foxes and their implications for canid vision. Vis. Neurosci. 10, 173180. (doi:10.1017/S0952523800003291)

Jacobs, G. H., Deegan II, J. F., Neitz, J. A., Crognale, M. A. \& Neitz, M. $1993 b$ Photopigments and color vision in the nocturnal monkey. Aotus Vision Res. 33, 1773-1783. (doi:10.1016/0042-6989(93)90168-V)

Jacobs, G. H., Deegan II, J. F., Neitz, J., Murphy, B. P., Miller, K. V. \& Marchinton, R. L. 1994 Electrophysiological measurements of spectral mechanisms in the retinas of two cervids: white-tailed deer (Odocoileus virginianus) and fallow deer (Dama dama). F. Comp. Physiol. A 174, 551-557.

Jacobs, G. H., Neitz, M., Deegan, J. F. \& Neitz, J. $1996 a$ Trichromatic colour vision in New World monkeys. Nature 382, 156-158. (doi:10.1038/382156a0)

Jacobs, G. H., Neitz, M. \& Neitz, J. $1996 b$ Mutations in $\mathrm{S}$-cone pigment genes and the absence of colour vision in two species of nocturnal primate. Proc. R. Soc. B 263, 705-710. (doi:10.1098/rspb.1996.0105)

Jacobs, G. H., Fenwick, J. A. \& Williams, G. A. 2001 Conebased vision of rats for ultraviolet and visible lights. f. Exptl. Biol. 204, 2439-2446.

Jacobs, G. H., Williams, G. A., Cahill, H. \& Nathans, J. 2007 Emergence of novel color vision in mice engineered to express a human cone photopigment. Science 315, 1723-1725. (doi:10.1126/science.1138838)

Kaskan, P. M., Franco, E. C. S., Yamada, E. S., Silveira, L. C., Darlington, R. B. \& Finlay, B. L. 2005 Peripheral variability and central constancy in mammalian visual system evolution. Proc. R. Soc. B 272, 91-100. (doi:10. 1098/rspb.2004.2925)

Kelber, A., Vorobyev, M. \& Osorio, D. 2003 Animal colour vision-behavioural tests and physiological concepts. Biol. Rev. 78, 81-118. (doi:10.1017/S1464793102005985)

Kemp, T. S. 2005 The origin and evolution of mammals. Oxford, UK: Oxford University Press.

Lee, B. B. 2004 Paths to colour in the retina. Clin. Exp. Optom. 87, 239-248. (doi:10.1111/j.1444-0938.2004. tb05054.x)

Levenson, D. H. \& Dizon, A. 2003 Genetic evidence for the ancestral loss of SWS cone pigments in mysticete and odontocete cetaceans. Proc. R. Soc. B 270, 673-679. (doi:10.1098/rspb.2002.2278)

Levenson, D. H., Ponganis, P. J., Crognale, M. A., Deegan II, J. F., Dizon, A. \& Jacobs, G. H. 2006 Visual pigments of marine carnivores: pinnipeds, polar bear, and sea otter. f. Comp. Physiol. A 192, 833-843. (doi:10.1007/s00359006-0121-x)

Loop, M. S., Millican, C. L. \& Thomas, S. R. 1987 Photopic spectral sensitivity of the cat. F. Physiol. 382, 537-553.

Lythgoe, J. N. \& Partridge, J. C. 1989 Visual pigments and the acquisition of visual information. f. Exp. Biol. 146, $1-20$.

Martin, P. R. 1998 Colour processing in the retina: recent progress. F. Physiol. 513, 631-638. (doi:10.1111/j.14697793.1998.631ba.x)

Martin, R. D. \& Ross, C. F. 2005 The evolutionary and ecological context of primate vision. In The primate visual system: a comparative approach (ed. J. Kremers). West Sussex, UK: John Wiley \& Sons, Ltd.
Merbs, S. L. \& Nathans, J. 1993 Role of hydroxyl-bearing amino acids in differentially tuning the absorption spectra of the human red and green cone pigments. Photochem. Photobiol. 58, 706-710. (doi:10.1111/j.1751-1097.1993. tb04956.x)

Mollon, J. D., Bowmaker, J. K. \& Jacobs, G. H. 1984 Variations of colour vision in a New World primate can be explained by polymorphism of retinal photopigments. Proc. R. Soc. B 222, 373-399. (doi:10.1098/rspb. 1984.0071)

Mollon, J. D., Estevez, O. \& Cavonius, C. R. 1990 The two subsystems of colour vision and their roles in wavelength discrimination. In Vision: coding and efficiency (ed. C. Blakemore), pp. 119-131. Cambridge, UK: Cambridge University Press.

Nathans, J., Thomas, D. \& Hogness, D. S. 1986 Molecular genetics of human color vision: the genes encoding blue, green and red pigments. Science 232, 193-202. (doi:10.1126/science.2937147)

Neitz, J. \& Jacobs, G. H. 1989 Spectral sensitivity of cones in an ungulate. Vis. Neurosci. 2, 97-100. (doi:10.1017/ S0952523800011949)

Newman, L. A. \& Robinson, P. R. 2006 The visual pigments of the West Indian manatee (Trichechus manatus). Vision Res. 46, 3326-3330. (doi:10.1016/j.visres.2006.03.010)

Nuboer, J. F. W., vanNuys, W. M. \& Wortel, J. F. 1983 Cone systems in the rabbit retina revealed by ERG-nulldetection. F. Comp. Physiol. A 151, 347-351.

Osorio, D. \& Vorobyev, M. 1996 Colour vision as an adaptation to frugivory in primates. Proc. R. Soc. B 263, 593-599. (doi:10.1098/rspb.1996.0089)

Osorio, D. \& Vorobyev, M. 2005 Photoreceptor spectral sensitivities in terrestrial animals: adaptations for luminance and colour vision. Proc. R. Soc. B 272, 1745-1752. (doi:10.1098/rspb.2005.3156)

Osorio, D., Smith, A. C., Vorobyev, M. \& Buchanan-Smith, H. M. 2004 Detection of fruit and the selection of primate visual pigments for color vision. Am. Nat. 164, 696-708. (doi:10.1086/425332)

Parraga, C. A., Troscianko, T. \& Tolhurst, D. J. 2002 Spatiochromatic properties of natural images and human vision. Curr. Biol. 12, 483-587. (doi:10.1016/S0960-9822(02) 00718-2)

Parry, J. W. L. \& Bowmaker, J. K. 2002 Visual pigment coexpression in guinea pig cones: a microspectrophotometric study. Invest. Ophthalmol. Vis. Sci. 43, 1662-1665.

Peichl, L. 2005 Diversity of mammalian photoreceptor properties: adaptations to habitat and lifestyle? Anat. Rec. A 287A, 1001-1012.

Peichl, L. \& Moutairou, K. 1998 Absence of short-wavelength sensitive cones in the retinae of seals (Carnivora) and African giant rats (Rodentia). Eur. F. Neurosci. 10, 2586-2594. (doi:10.1046/j.1460-9568.1998.00265.x)

Peichl, L., Kunzle, H. \& Vogel, P. 2000 Photoreceptor types and distributions in the retinae of insectivores. Vis. Neurosci. 17, 937-948. (doi:10.1017/S0952523800176138)

Pointer, M. R. \& Attridge, G. G. 1998 The number of discernable colours. Color Res. Appl. 23, 52-54. (doi:10.1002/(SICI) 1520-6378(199802)23:1<52::AIDCOL8 $>3.0 . \mathrm{CO} ; 2-2)$

Regan, B. C., Julliot, C., Simmen, B., Vienot, F., CharlesDominique, P. \& Mollon, J. D. 2001 Fruits, foliage and the evolution of primate colour vision. Phil. Trans. $R$. Soc. B 356, 229-283.

Schnapf, J. L., Kraft, T. W., Nunn, B. J. \& Baylor, D. A. 1988 Spectral sensitivity of primate photoreceptors. Vis. Neurosci. 1, 255-261. (doi:10.1017/S0952523800001917)

Smith, V. C. \& Pokorny, J. 1977 Large-field trichromacy in protanopes and deuteranopes. F. Opt. Soc. Am. 67, 213-220. (doi:10.1364/JOSA.67.000213) 
Smith, A. C., Buchanan-Smith, H. M., Surridge, A. K., Osorio, D. \& Mundy, N. I. 2003 The effect of colour vision status on the detection and selection of fruits by tamarins (Saguinus spp.). F. Exp. Biol. 206, 3159-3165. (doi:10.1242/jeb.00536)

Solomon, S. G. \& Lennie, P. 2007 The machinery of colour vision. Nat. Neurosci. Rev. 8, 276-286. (doi:10.1038/ nrn2094)

Springer, M. S. \& Murphy, W. J. 2007 Mammalian evolution and biomedicine: new views from phylogeny. Biol. Rev. 82, 375-392. (doi:10.1111/j.1469-185X.2007.00016.x)

Strachan, J., Chang, L.-Y. E., Wakefield, M. J., Marshall Graves, J. A. \& Deeb, S. S. 2004 Cone visual pigments of the Australian marsupials, the stripe-faced and fat-tailed dunnarts: sequence and inferred spectral properties. Vis. Neurosci. 21, 223-229. (doi:10.1017/ S0952523804213281)

Surridge, A. K., Osorio, D. \& Mundy, N. I. 2003 Evolution and selection of trichromatic vision in primates. Trends Ecol. Evol. 18, 198-206. (doi:10.1016/S0169-5347(03) 00012-0)

Tan, Y. \& Li, H. 1999 Trichromatic vision in prosimians. Nature 402, 36. (doi:10.1038/46947)

Tan, Y., Yoder, A. D., Yamashita, N. \& Li, H. 2005 Evidence from opsin genes rejects nocturnality in ancestral primates. Proc. Natl Acad. Sci. USA 41, 14 712-14 716.

Vogel, E. R., Neitz, M. \& Dominy, N. J. 2007 Effect of color vision phenotype on the foraging of wild white-faced capuchins Cebus capucinus. Behav. Ecol. 18, 292-297. (doi:10.1093/beheco/arl082)
Wakefield, M. J., Anderson, M., Chang, E., Wei, K.-J., Kaul, R., Marshall Graves, J. A., Grutzner, F. \& Deeb, S. S. 2008 Cone visual pigments of monotremes: filling the phylogenetic gap. Vis. Neurosci. 25, 257-264. (doi:10.1017/S09525238080255)

Wang, D., Oakley, T., Mower, J., Shimmin, L. C., Yim, S., Honeycutt, R. L., Tsao, H. \& Li, H. 2004 Molecular evolution of bat color vision genes. Mol. Biol. Evol. 21, 295-302. (doi:10.1093/molbev/msh015)

Wässle, H. 2004 Parallel processing in the mammalian retina. Nat. Neurosci. 19, 747-757.

Weitz, C. J., Miyake, Y., Shinzato, K., Montag, E., Zrenner, E., Went, L. N. \& Nathans, J. 1992 Human tritanopia associated with two amino acid substitutions in the blue sensitive opsin. Am. F. Hum. Genet. 50, 498-507.

Williams, G. A., Calderone, J. B. \& Jacobs, G. H. 2005 Photoreceptors and photopigments in a subterranean rodent, the pocket gopher (Thomomys bottae). F. Comp. Physiol. A 191, 125-134. (doi:10.1007/s00359-004-0578-4)

Yokoyama, S. 2000 Molecular evolution of vertebrate visual pigments. Prog. Retinal Eye Res. 19, 385-419. (doi:10. 1016/S1350-9462(00)00002-1)

Yokoyama, S., Takenaka, N., Agnew, D. W. \& Shoshani, J. 2005 Elephants and human color-blind deuternanopes have identical sets of visual pigments. Genetics 170, 335-344. (doi:10.1534/genetics.104.039511)

Yokoyama, S., Yang, H. \& Starmer, W. T. 2008 Molecular basis of spectral tuning in the red- and green-sensitive (M/LWS) pigments in vertebrates. Genetics 179, $2037-$ 2043. (doi:10.1534/genetics.108.090449) 